\title{
Dielectric Behaviour of Some Woven Fabrics on the Basis of Natural Cellulosic Fibers
}

\author{
Florin St. C. Mustata ${ }^{1}$ and Adriana Mustata ${ }^{2}$ \\ ${ }^{1}$ Engineering Technology, Purdue University, Calumet, 2200 169th Street, Hammond, IN 46323-2094, USA \\ ${ }^{2}$ Faculty of Textiles and Industrial Management, "Gh. Asachi" Technical University of Jassy, \\ Prof. Dimitrie Mangeron Boulevard No. 53, 700050 Jassy, Romania \\ Correspondence should be addressed to Adriana Mustata; amustata@tex.tuiasi.ro
}

Received 26 May 2013; Revised 1 October 2013; Accepted 8 October 2013; Published 21 January 2014

Academic Editor: Yuanhua Lin

Copyright (C) 2014 F. St. C. Mustata and A. Mustata. This is an open access article distributed under the Creative Commons Attribution License, which permits unrestricted use, distribution, and reproduction in any medium, provided the original work is properly cited.

\begin{abstract}
The electrical permittivity of the weaves obtained from natural cellulosic yarns or mixed with synthetic fibers was established with capacitor method. The highest value of relative electrical permittivity in case of the woven fabric from natural cellulosic fibers has been observed at the weave made of pure hemp (13.55) and the lowest at the weave obtained from the pure jute-weave packing (1.87). Electrical permittivity value of the pure jute weave packing is comparable to that of the permittivity for the glass thread, when the work conditions are as follows: temperature $25^{\circ} \mathrm{C}$ and air humidity $35 \%$. The relative electrical permittivity of the weave is depending on the degree of crimping yarns especially in the weft direction, technological density in direction of the warp and weft, and surface mass of the weave.
\end{abstract}

\section{Introduction}

Electrical and electrostatic behaviours of the textiles are important for practical applications. Dielectric properties of textile materials have been studied for a long time by many researchers [1-10]. Thus, static friction, one of the main methods of electrification of bodies, was first described by Thales of Miletus (VI century BC) on the basis of observations made by a weaver who found that by rubbing amber with a woolen cloth, it will achieve the property of attracting light bodies [8].

Electrical isolation of current paths of machinery, equipment and electrical installations are made using dielectric materials or electrical insulator, which theoretically have infinite resistivity and appreciable permittivity uninfluenced by environmental conditions and temperature or the variation in time of the electric field where they are used. In real life, insulators have high resistivity, but not infinite permittivity, and properties that vary with the factors previously mentioned and their physical and chemical structure [5-8].

Dielectric materials have the electromagnetic fundamental property to be polarized under the influence of the electric field. Cellulose is one of the dielectrics which can be electronically and structurally polarized, with ionic polarization. The permittivity values of solid dielectrics vary according to the structural features of the dielectric material. Most of the dielectrics with their crystalline structure, although linear, are anisotropic [8]. Natural cellulosic fibers which belong to the category of flax, hemp, jute, and cotton have high hygroscopicity and their electrical properties are closely related to moisture content. Theoretically, the mixing of the natural cellulosic fibers with synthetic fibers in different proportions may vary their electrical resistance. Thus, a method to reduce the static electricity charge of the textile fibers can be the mixing process of different types of fibers. Textile fibers absorb a large amount of electrons [11, 12]. For example, cotton fibers are charged with negative electricity; polyamide fibers are filled with positive electricity [11]. In the same way the electrical permittivity will increase in nonwet conditions. In high humidity environments the blends of natural and chemical fibers will have low electrostatic charge because the electrical resistance varies inversely with moisture content [13]. 
TABLE 1: Chemical composition of hemp, flax, jute, and cotton fibers.

\begin{tabular}{|c|c|c|c|c|}
\hline $\begin{array}{l}\text { Type of } \\
\text { fibers }\end{array}$ & $\begin{array}{c}\text { Cellulose } \\
(\%)\end{array}$ & $\begin{array}{c}\text { Lignins } \\
(\%)\end{array}$ & $\operatorname{Pectin}(\%)$ & $\begin{array}{r}\text { Density } \\
\left(\mathrm{g} \cdot \mathrm{cm}^{-3}\right)\end{array}$ \\
\hline Hemp & $67^{*}-77^{* *}$ & $3-6$ & $4-10$ & $1.43-1.48$ \\
\hline Flax & $84^{*}-93^{* *}$ & $0.6-4$ & $3-4$ & $1.43-1.54$ \\
\hline Jute & $60-73$ & \multicolumn{2}{|c|}{$25-27$} & 1.5 \\
\hline Cotton & $94-96$ & - & 1.9 & $1.48-1.52$ \\
\hline
\end{tabular}

${ }^{*}$ Raw fibers; ${ }^{* *}$ bleached fibers.

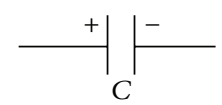

FIGURE 1: RC group with high capacitive component.

The aim of the present paper is to reveal the possibilities of achievement of the some dielectrics environmentally friendly with electrical permittivity controlled. The electrical permittivity for different textiles from cellulose natural fibers like hemp, flax, jute, and cotton $100 \%$ or mixtures from synthetic and natural textiles fibers was studied. These natural cellulosic fibers have the basic component greater than $60 \%$ $[11,12]$, see Table 1 .

The correlation between the electrical permittivity and the main structural parameters of the fabric [14], surface mass and technological density of yarns in the direction of warp and in direction of weft, was studied. The practical application of this examined property is important in protection clothes or textile for dedicated behaviour in environments sensitive at electrical discharges.

\section{Theoretical Aspects}

Electrical behaviour of the woven structures changes according to the hygroscopicity of the blending fibers and of the ambient humidity. Thus, the fabric will behave as a group RC (see Figure 1) in which the capacitive behaviour will prevail in conditions of low humidity and will diminish with increasing humidity. This means that the fabric will electrify more easily in dry environment no matter the quantity of natural fiber content in the mixture is. In high humidity environments the fabric with a high content of cellulosic fibers and a low content of synthetic fibers will act as an RC group with highly resistive component which will prevail in the capacitive component and the fabric will not electrify more easily. This kind of fabric will be suitable for use in industrial areas with high voltages. In this case the electrical behaviour of the fabric can be assimilated with the RC group presented in Figure 2.

Evaluation of the electrical behaviour of fabrics studied in this paper was made using relative electric permittivity. Textile materials analyzed were used as dielectric for a capacitor with geometrical configuration: $A$-surface electrode (length: $257 \mathrm{~mm}$; width: $140 \mathrm{~mm}$ ) and $d$-thickness of weave studied.

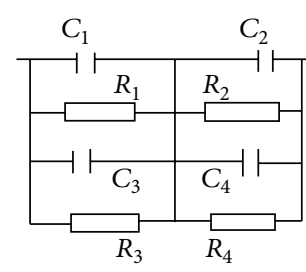

FIGURE 2: RC group with highly resistive and low capacitive components.

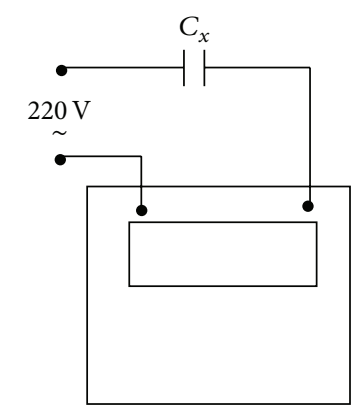

FIGURE 3: The installation wiring diagram where the woven fabric represents the equivalent of a capacitor $\left(C_{x}\right)$.

Electric permittivity was calculated with relation (1):

$$
\xi=\frac{c \cdot d}{A}
$$

where $c$ is the electric capacity, $F ; d$ is thickness of the weave, $\mathrm{mm}$; and $A$ is area of the capacitor reinforcement, $\mathrm{mm}^{2}$.

Relative electric permittivity allows comparing the electrical point of view of a given environment with vacuum or air. This shows how many times the electrical force of interaction in vacuum is higher than that in environment. The next equation can be used to calculate the relative permittivity:

$$
\xi_{r}=\frac{F_{0}}{F}=\frac{\xi}{\xi_{0}},
$$

where $F_{0}$ is the electric force of interaction in a vacuum; $F$ is electric force of interaction in environment analysed; $\xi_{0}$ is electrical permittivity of the given environment; and $\xi$ is electrical permittivity of vacuum or air.

Electric permittivity of vacuum or air is universal constant with the value $\xi_{0}=8.85 \cdot 10^{-12} \mathrm{~F} / \mathrm{m}$.

Relative electrical permittivity of air is close to unity $\left(\xi_{r_{\text {air }}}=1.00059\right)$. It is considered that the electrical properties of air are the same as vacuum.

\section{Experimental}

3.1. Materials. In this work weaves were studied from cellulosic natural fibers like flax, hemp, jute, cotton $100 \%$ or mixtures, polyester $100 \%$, and glass thread. The hemp and flax weaves used in this study came from Integrata Pascani (Romania). The following articles were tested: Suceava, Sava, Nabucco, Rares, Lori, Livia, Zorba, and Ina. The jute weaves 


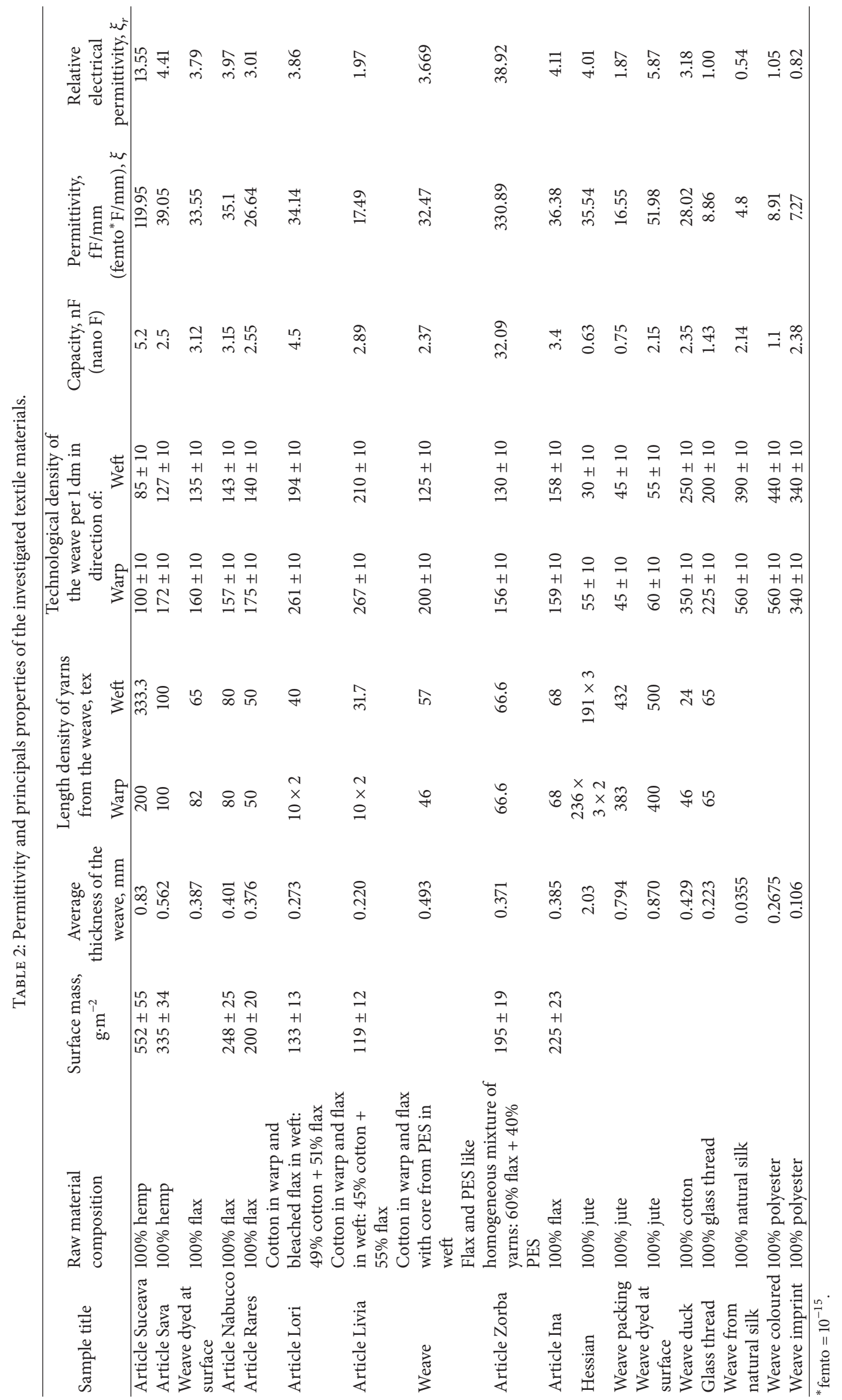




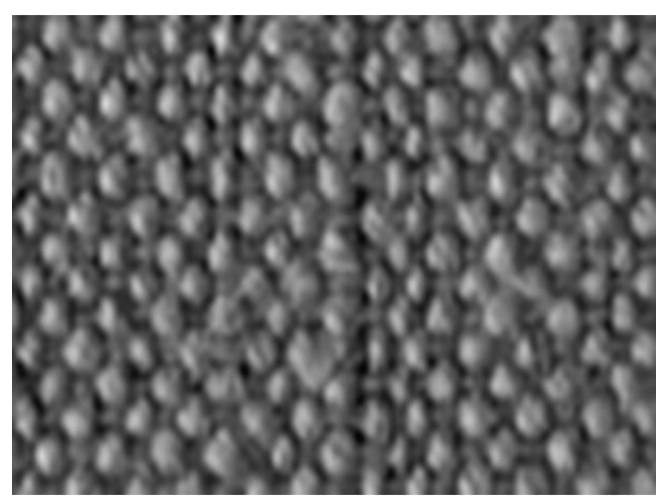

(a) Sample Suceava, $1.8 \mathrm{x}$

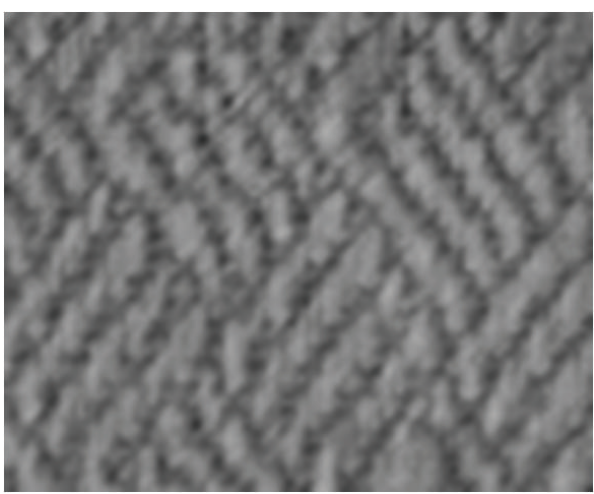

(b) Sample Sava, $1.8 \mathrm{x}$

FIgURE 4: Images of weaves from hemp.

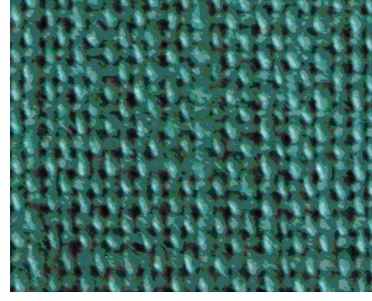

(a) Sample Nabucco, 2.5x

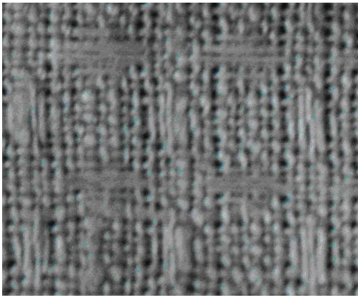

(b) Sample Rares, $2 \mathrm{x}$

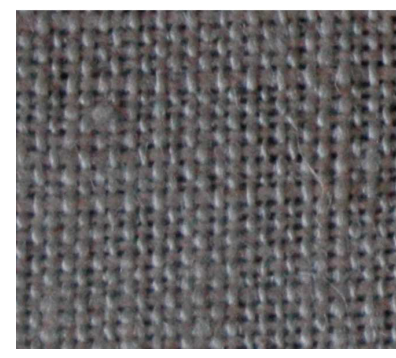

(c) Sample Ina, $2 \mathrm{x}$

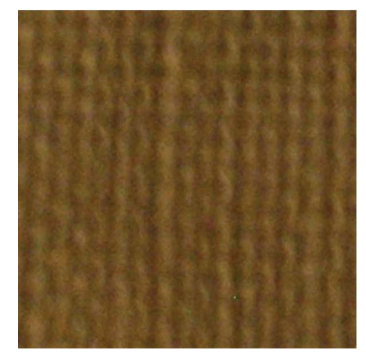

(d) Sample from flax dyed at surface, $2.5 \mathrm{x}$

FIgURE 5: Images of weaves from flax.

studied came from Textila Iasi (Romania). The article from cotton came from Tesatura Iasi (Romania).

3.2. Methods. The variation of the electric permittivity related to the specific material was measured with capacitor method. The installation wiring diagram is shown in Figure 3. Measuring of the capacity of the woven fabric was performed with Ultraprecision Capacitance Bridge AH 2700 A (ANDEENHAGERLING- $50 \mathrm{~Hz}-20 \mathrm{kHz}$ ).

The thickness of the woven fabric was measured on a MICROMASTER capa $\mu$ system IP54 TESA micrometer. The measuring of the capacity and of the thickness of the fabric was made in ten points on the fabric surface.

Measurements were conducted in the following work conditions: temperature $25^{\circ} \mathrm{C}$, air relative humidity $35 \%$, and the fabric in a single layer.

Electric permittivity was calculated with relation (1) and the relative electric permittivity with (2).

\section{Results and Discussion}

In Table 2 the values of the electrical permittivity and the main properties of the weaves from flax, hemp, jute, cotton, blends, polyester, and glass are presented, as the average of 10 measurements.
Analysis of the values presented in Table 2 permits the following comments to be drawn. The samples made of hemp are named Suceava and Sava and come from the same place: Integrata Pascani (Romania). Hemp fibers that used to produce the articles Suceava and Sava have the same quality and the same chemical composition (Table 1). The two articles from hemp have different structure of the weave, see Figure 4.

Electrical permittivity of three times higher recorded in case of the article Suceava in comparison with article Sava may be attributed to the differences between mass surface unit of the fabrics (about 40\%), see Table 2. The warp and the weft yarns of the article Sava are twice thinner than those of the article Suceava (Table 2). Capacity measurement was made on available fabrics to a single layer. Usually, the thickness of the fabric depends on length density of yarns from warp and weft, the degree of crimping of yarns and technological density in the weave. These parameters influence the mass surface unit.

Flax fibres in the articles Nabuco, Rareş, Lori, Livia, Zorba, and Ina coming from the same place Integrata Pascani (Romania) have the same quality and chemical composition, see Table 1.

Articles Nabucco, Ina, and sample dyed at surface (100\% flax) have their relative electrical permittivity ranging between 3.79 and 4.11 . These nearby values may be attributed 


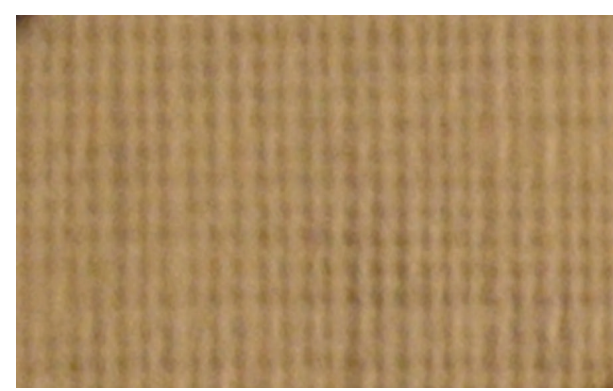

(a) Sample Livia, $5 \mathrm{x}$

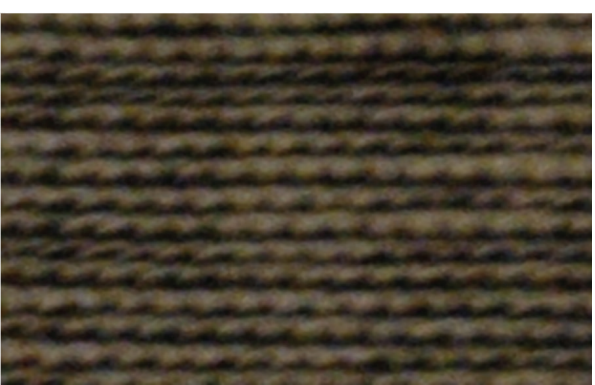

(b) Sample Lori, $5 \mathrm{x}$

Figure 6: Weaves from cotton in warp and flax in weft.

TABLE 3: The degree of crimping of yarns in the jute weaves.

\begin{tabular}{lcccc}
\hline \multirow{2}{*}{ Weave type } & \multicolumn{2}{c}{ Weave thickness, mm } & Degree of crimping of yarns in weave, \% & Relative electrical permittivity \\
& & Warp & Weft & 3.90 \\
Hessian & 2.03 & 1.73 & 3.24 & 1.70 \\
Weave packing from jute & 0.79 & 2.08 & 8.23 & 5.50 \\
Jute weave dyed at surface & 0.87 & 2.49 & & \\
\hline
\end{tabular}

to the similar structural characteristics of the three types of fabrics; see Figure 5.

Lower value of relative electrical permittivity (3.01) recorded for the article Rares (flax 100\%) may be attributed to smaller thickness and lower mass surface unit (50 tex and $200 \mathrm{~g} / \mathrm{m}^{2}$ ). The differences between these articles, as in the case of hemp articles, are due to structural parameters of the fabric.

Woven fabrics obtained from cellulose yarns or blends of natural fibers with polyester were also tested in terms of electrical behaviour.

For the article obtained from cotton yarns in warp and flax in weft in equal proportions, the different values of the relative electrical permittivity may be attributed to various structures and characteristics of the weave.

Articles Livia and Lori which have in their structure the same type of fibers present different permittivity, a fact that can be explained by the structure of the weave; see Figure 6 . The lower permittivity of article Livia in comparison with article Lori may be due to thickness and the higher threads per $1 \mathrm{dm}$ in direction of the weft which implied the inclusion of small amounts of air.

Mass surface unit higher for article Lori determines the increasing of the relative electrical permittivity by about $40 \%$ in comparison with article Livia. Weaves from cotton $100 \%$ have similar electrical behaviour with $100 \%$ flax.

In case of article Zorba obtained from yarns with homogeneous mixture (60\% flax and $40 \%$ polyester), relative electrical permittivity recorded is nearest 39, about 10 times higher than for articles Ina, Nabucco, and Rares. This fact may be attributed to the polyester fibers from mixture.

The three weaves from jute (Hessian type, for packing, and dyed at surface) have different values for relative permittivity depending on their structural characteristics; see Table 2. One of these characteristics, important for thick fabrics, is the degree of crimping of yarns in the weave. This can be calculated using the following equation [14]:

$$
a=\frac{L_{\text {yarn }}-L_{\text {weave }}}{L_{\text {yarn }}} \cdot 100 \text {, }
$$

where $L_{\text {yarn }}$ is length of yarn extracted from the weave; $L_{\text {weave }}$ is length of the weave; and $a$ is degree of crimping of yarns in the fabric.

Mean values of the degree of crimping of yarns in the jute weaves are summarized in Table 3.

Jute fabric for packing has the lower relative permittivity in comparison with the other articles from jute because this has the lowest technological density (Table 2).

Hessian type weave is more dense than the others because the warp yarns are twisted and the weft are cabled; see Figure 7. The average thickness of this is 2.5 times higher than that of jute packing weave and is reflected in the value of relative permittivity of 2.3 times higher. Often, the thickness of the weave depends on the linear density of the warp and weft yarns and their degree of crimping in the weave.

The higher relative permittivity of jute weave dyed at surface in comparison with the other two can be explained by the great level of crimping yarns in their structure (Table 3).

The relative permittivity of the weaves obtained from natural cellulose was compared with the other types of weaves (from natural silk, fiber glass, or polyester, see Figure 8). The average values of relative permittivity for weaves obtained from natural silk, fiber glass, or polyester are also presented in Table 2.

For weaves made from natural cellulose fibers, based on data in Table 2, using GRAF 4WIN and STATISTICA 99 softwares, the correlation between relative permittivity and the structural parameters was established (mass surface unit 


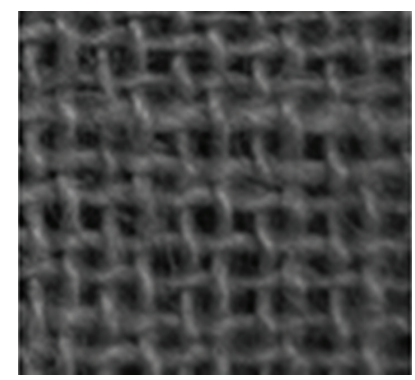

(a) Packing weave from jute, $1.7 \mathrm{x}$

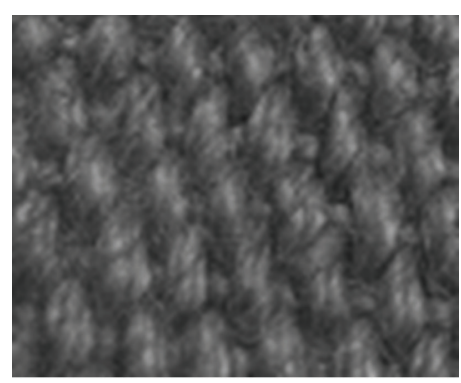

(b) Hessian, $1.7 \mathrm{x}$

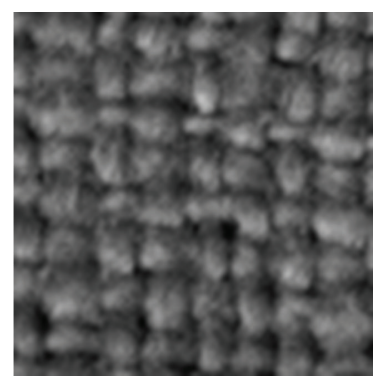

(c) Jute weave dyed at surface, $2.5 \mathrm{x}$

FIGURE 7: Images of weaves from jute.

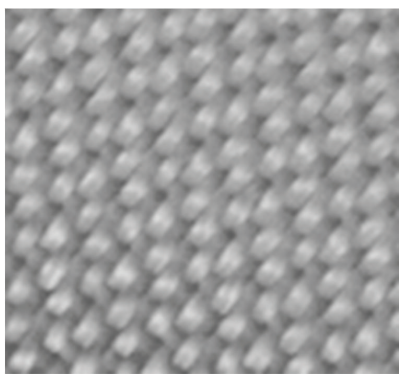

(a) Glass thread, $4.3 \mathrm{x}$

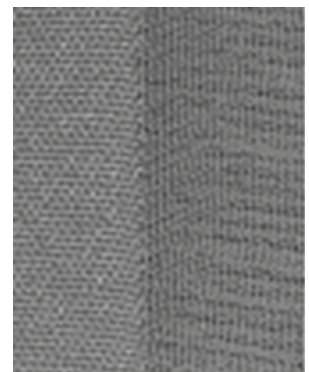

(b) Weave from polyester mass coloured, $4.3 \mathrm{x}$

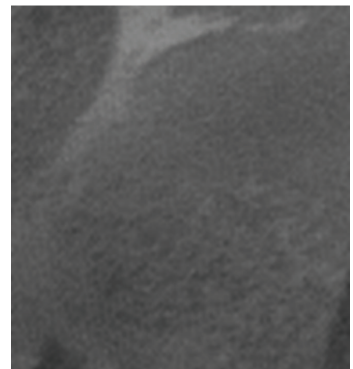

(c) Weave imprint from polyester, $3.4 \mathrm{x}$

FIGURE 8: Images of weaves from glass thread or polyester.

and technological density per $1 \mathrm{dm}$ in direction of warp and in direction of weft).

Variation of the relative permittivity for weaves as function of the surface mass in the range $100-600 \mathrm{~g} / \mathrm{m}^{2}$ is represented in Figure 9.

Figure 9 shows that, in case of the thin weaves with surface mass up to $350 \mathrm{~g} / \mathrm{m}^{2}$, relative permittivity does not exceed value 4 . For the weaves with surface mass higher than $350 \mathrm{~g} / \mathrm{m}^{2}$, the relative permittivity values increases were pronounced. This may be explained by reduced porosity of this type of weave.

Simultaneous influence of the threads per $1 \mathrm{dm}$ in the direction of warp and weft on the relative electrical permittivity of the $100 \%$ cellulosic materials was established using statistical programs. Based on experimental data from Table 2, a regression equation (4) was obtained and used to predict the electrical behaviour of the weaves

$$
\begin{aligned}
z= & 2.616-0.071 \cdot x+0.159 \cdot y+0.001 \cdot x^{2} \\
& -0.002 \cdot x \cdot y+0.00028 \cdot y^{2}
\end{aligned}
$$

where $x$ represents technological density in direction of warp (yarns/dm); $y$-technological density in direction of weft (yarns/dm); $z$-relative electric permittivity.

The regression equation obtained from the experimental data expresses the simultaneous influence of the two independent parameters ( $x$ and $y$ ) taken into account in the study of the relative electrical permittivity of natural cellulosic weaves.
The coefficient of multiple correlation $R$ for the regression equation (4) was 0.29 and the $R$ Square coefficient was 0.08 . This means that only $8 \%$ from the total variation of the measured values for the dependent variable (relative electrical permittivity) is caused by the influence of the technological density in direction of warp and weft (the independent variables). Other factors that influence the electrical permittivity are as follows: chemical structure of fibers, weave thickness, degree of the crimping of the yarns, and so on. Cellulose (over $60 \%$ ), the basic component of the studied fabrics from flax, hemp, and jute, determines the electrical behaviour of these products.

Using the regression equation (4) in Figure 10 was presented the threedimensional response surface plot.

For the imposed values of the relative electrical permittivity, the regression equation (4) allows the calculation of the technological density values in warp and weft.

The constant-level curves shown in Figure 11 may be employed for establishing the technological density in direction of warp and weft for a certain level of the relative electrical permittivity of the natural cellulosic weaves.

\section{Conclusions}

The highest value of the relative electrical permittivity in case of the woven fabrics studied has been observed at the weave made of pure hemp (13.55), and the lowest at the weave obtained from the pure jute-weave packing (1.87). The value 


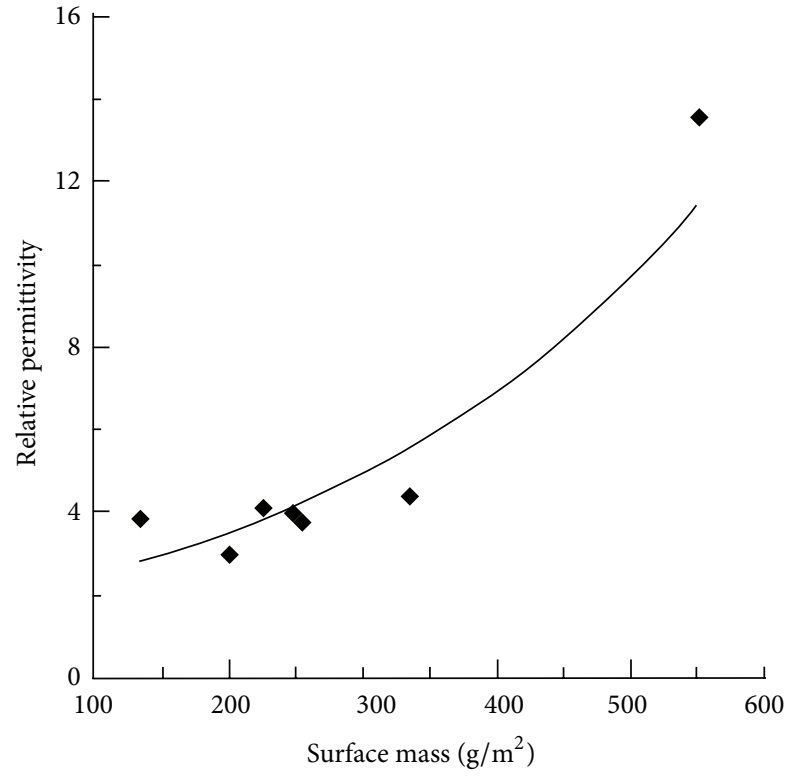

FIGURE 9: Variation of relative permittivity for weaves from natural cellulosic fibers depending on mass surface.

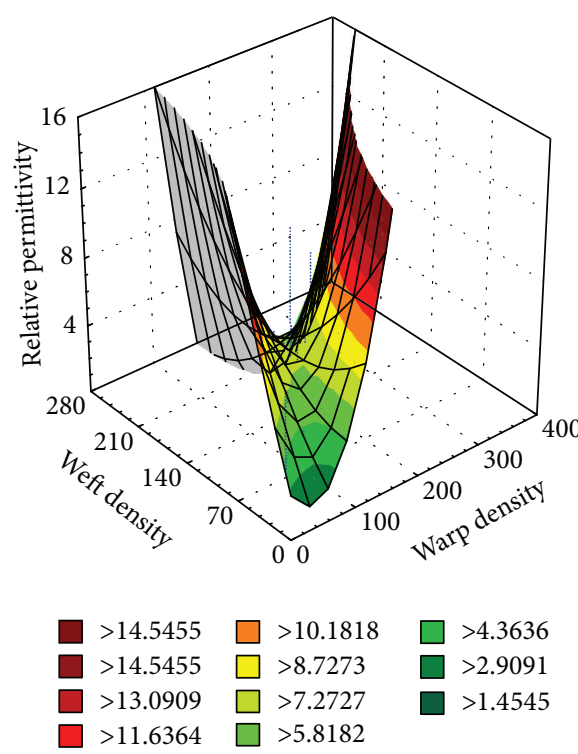

FIGURE 10: Simultaneous influence of the technological density (yarns per $1 \mathrm{dm}$ ) in direction of warp and weft on the relative electrical permittivity of natural cellulosic weaves. $3 \mathrm{D}$ surface plot $\left(\right.$ NEW.STA $\left.10 \mathrm{v}^{*} 22 \mathrm{c}\right) z=2.6156-0.0715 \cdot x+0.1591 \cdot y+0.001 \cdot x^{2}-$ $0.0018 \cdot x \cdot y+0.0003 \cdot y^{2}$.

of the electrical permittivity of the pure jute weave packing is comparable to that of the permittivity for the glass thread at $25^{\circ} \mathrm{C}$ and $35 \%$ air humidity.

For the imposed values of the relative electrical permittivity, the regression equation established allows the calculation of the technological density values in warp and weft for the weave.

In case of the thin weaves with surface mass up to $350 \mathrm{~g} / \mathrm{m}^{2}$, relative permittivity does not exceed value 4 . For

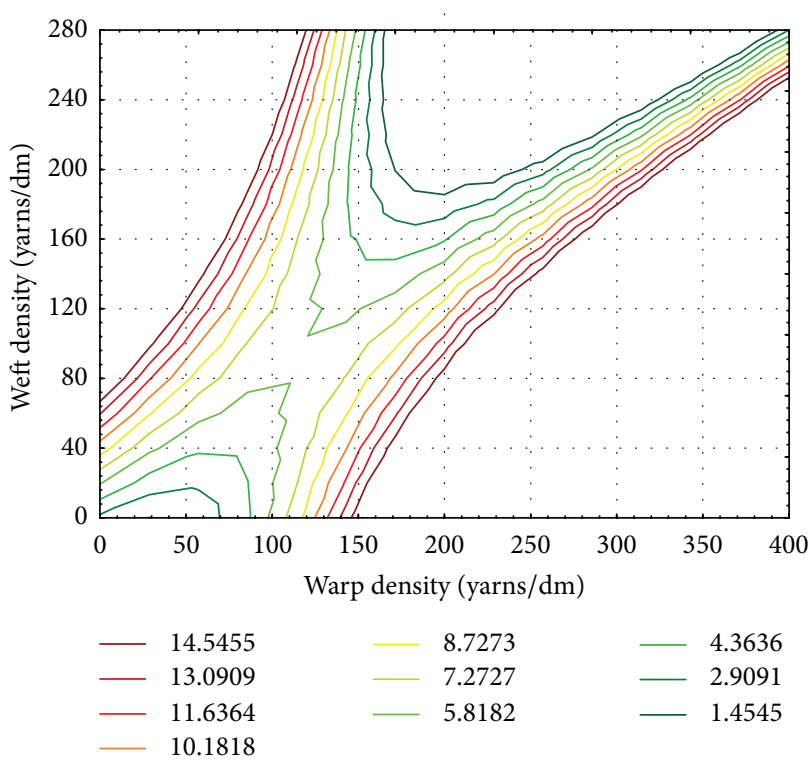

FIGURE 11: Constant level curves of the relative electrical permittivity of weaves from natural cellulosic fibres as a function of the threads per $1 \mathrm{dm}$ in direction of warp and in direction of weft. 3D contour plot (NEW.STA $\left.10 \mathrm{v}^{*} 22 \mathrm{c}\right) z=2.6156-0.0715 \cdot x+0.1591 \cdot y+0.001$. $x^{2}-0.0018 \cdot x \cdot y+0.0003 \cdot y^{2}$.

the weaves with surface mass higher than $350 \mathrm{~g} / \mathrm{m}^{2}$, the relative permittivity values increases were pronounced, until 14 .

Cellulose (over 60\%), the basic component of the studied fabrics from flax, hemp, and jute, is one of the important factors that determines the electrical behaviour of these products.

The important parameters of the fabric structure studied in this paper, which have influenced the relative electrical permittivity, were as follows: the degree of yarns crimping especially in the weft direction, the technological density in direction of the warp and the weft, and the surface mass of the fabric.

Change of the parameters of fabric structure from natural cellulosic fibers (surface mass and technological density) may vary the relative electrical permittivity between 2 and 14. The practical application of this examined property is important for the engineering use in protection clothes or textile for dedicated behaviour in environments sensitive at electrical discharges.

\section{Conflict of Interests}

The authors declare that there is no conflict of interests regarding the publication of this paper.

\section{References}

[1] B. Bailey and E. L. Phelps, "The capacitance of textile materials in relation to moisture content a," Textile Research Journal, vol. 9, no. 3, pp. 101-113, 1939. 
[2] J. W. S. Hearle, "11-The electrical resistance of textile materials: I. The influence of moisture content," The Journal of The Textile Institute, vol. 44, no. 4, pp. 117-143, 1953.

[3] J. W. S. Hearle, "Capacity, dielectric constant, and power factor of fiber assemblies," Textile Research Journal, vol. 24, no. 4, pp. 307-321, 1954.

[4] S. Varnaite, A. Vitkauskas, A. Abraitiene, V. Rubežiene, and V. Valiene, "The features of electric charge decay in the polyester fabric containing metal fibres," Medziagotyra, vol. 14, no. 2, pp. 157-161, 2008.

[5] K. A. Asanovic, T. A. Mihajlidi, S. V. Milosavljevic, D. D. Cerovic, and J. R. Dojcilovic, "Investigation of the electrical behavior of some textile materials," Journal of Electrostatics, vol. 65, no. 3, pp. 162-167, 2007.

[6] C. Modes, S. Malkmus, and F. Gora, "High K low loss dielectrics co-fireable with LTCC," Active and Passive Electronic Components, vol. 25, no. 2, pp. 141-145, 2002.

[7] K. Bal and V. K. Kothari, "Measurement of dielectric properties of textile materials and their applications," Indian Journal of Fibre and Textile Research, vol. 34, no. 2, pp. 191-199, 2009.

[8] N. Ida, Engineering Electromagnetics, Springer, New York, NY, USA, 2nd edition, 2004.

[9] L. Rattfält, M. Lindén, P. Hult, L. Berglin, and P. Ask, "Electrical characteristics of conductive yarns and textile electrodes for medical applications," Medical and Biological Engineering and Computing, vol. 45, no. 12, pp. 1251-1257, 2007.

[10] I. Kazani, C. Hertleer, G. de Mey, A. Schwarz, G. Guxho, and L. van Langenhove, "Electrical conductive textiles obtained by screen printing," Fibres and Textiles in Eastern Europe, vol. 90, no. 1, pp. 57-63, 2012.

[11] I. Ionescu-Muscel, Fibrele textile la sfarsit de mileniu, Tehnica, Bucharest, Romania, 1990.

[12] I. Vlad, Fibre Textile, Didactica si Pedagogica, Bucharest, Romania, 1964.

[13] C. A. Walker, "Effect of atmospheric humidity and temperature on the relation between moisture content and electrical conductivity of cotton," The Journal of the Textile Institute, vol. 12, no. 4, pp. 431-451, 1933.

[14] A. Marchis, M. Macovei, T. Muresan, and S. Ionescu, Structura si proiectarea tesaturilor, Tehnica, Bucharest, Romania, 1964. 

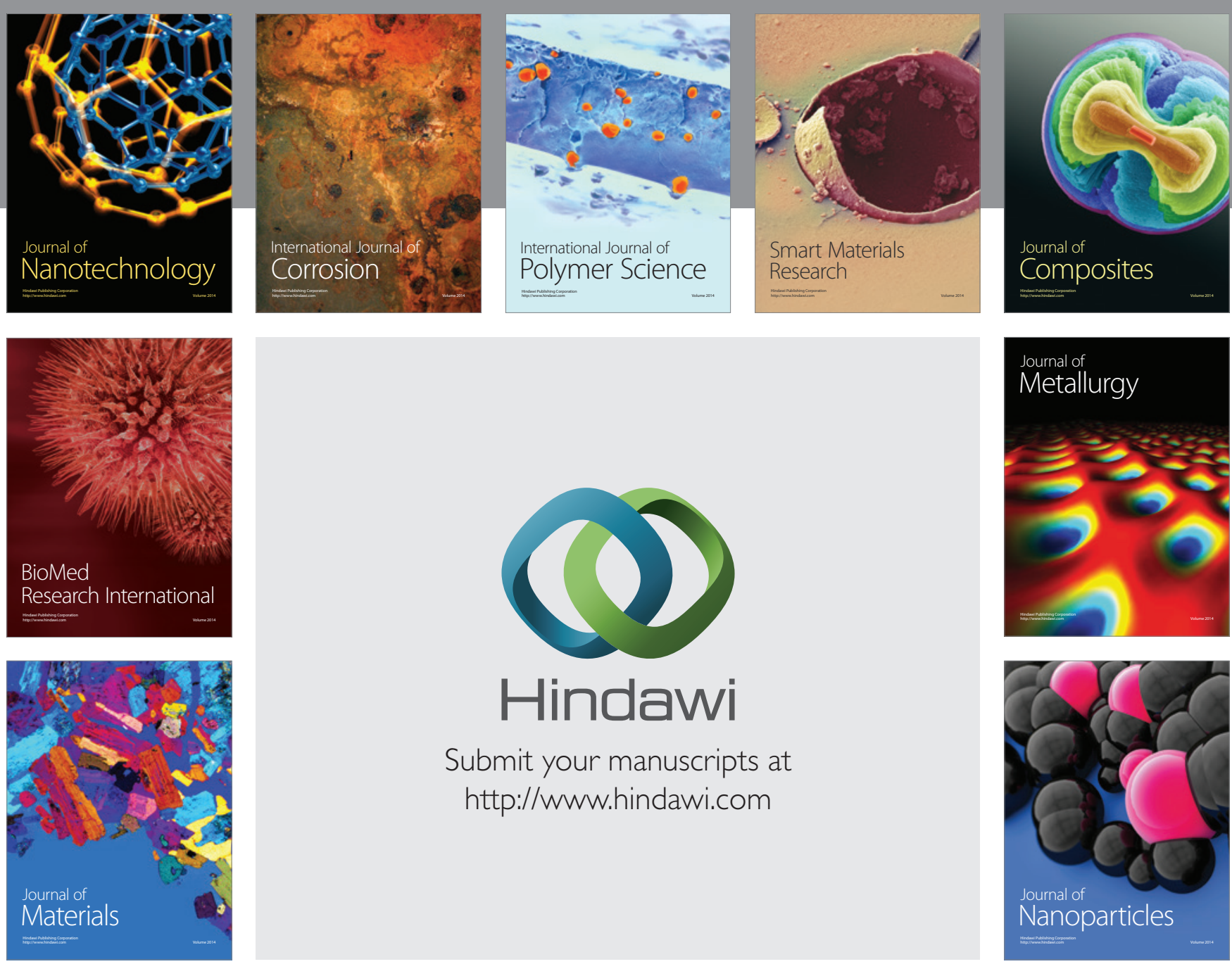

Submit your manuscripts at http://www.hindawi.com
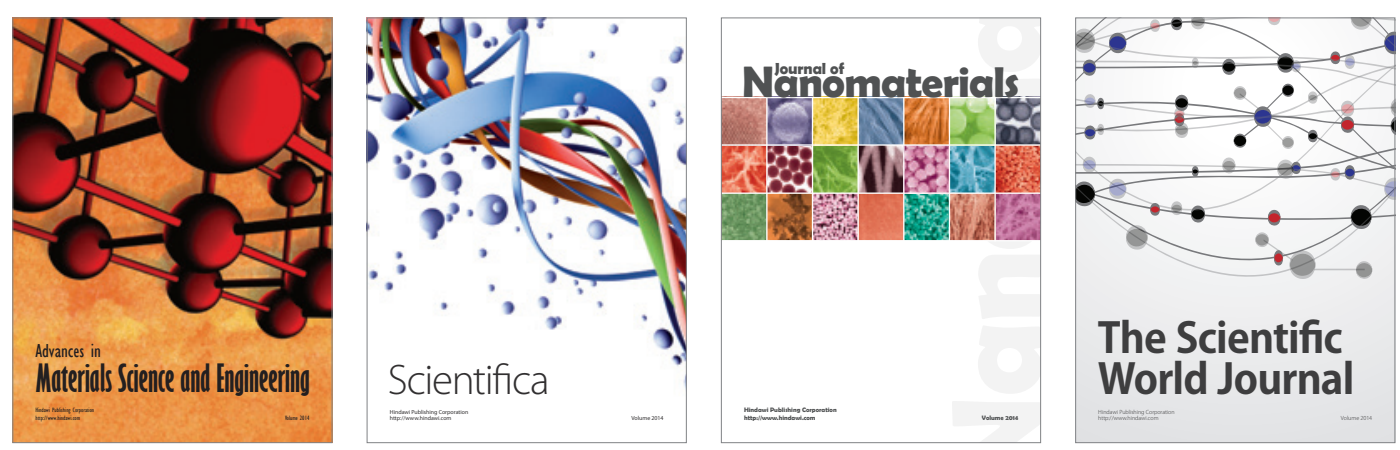

\section{The Scientific World Journal}
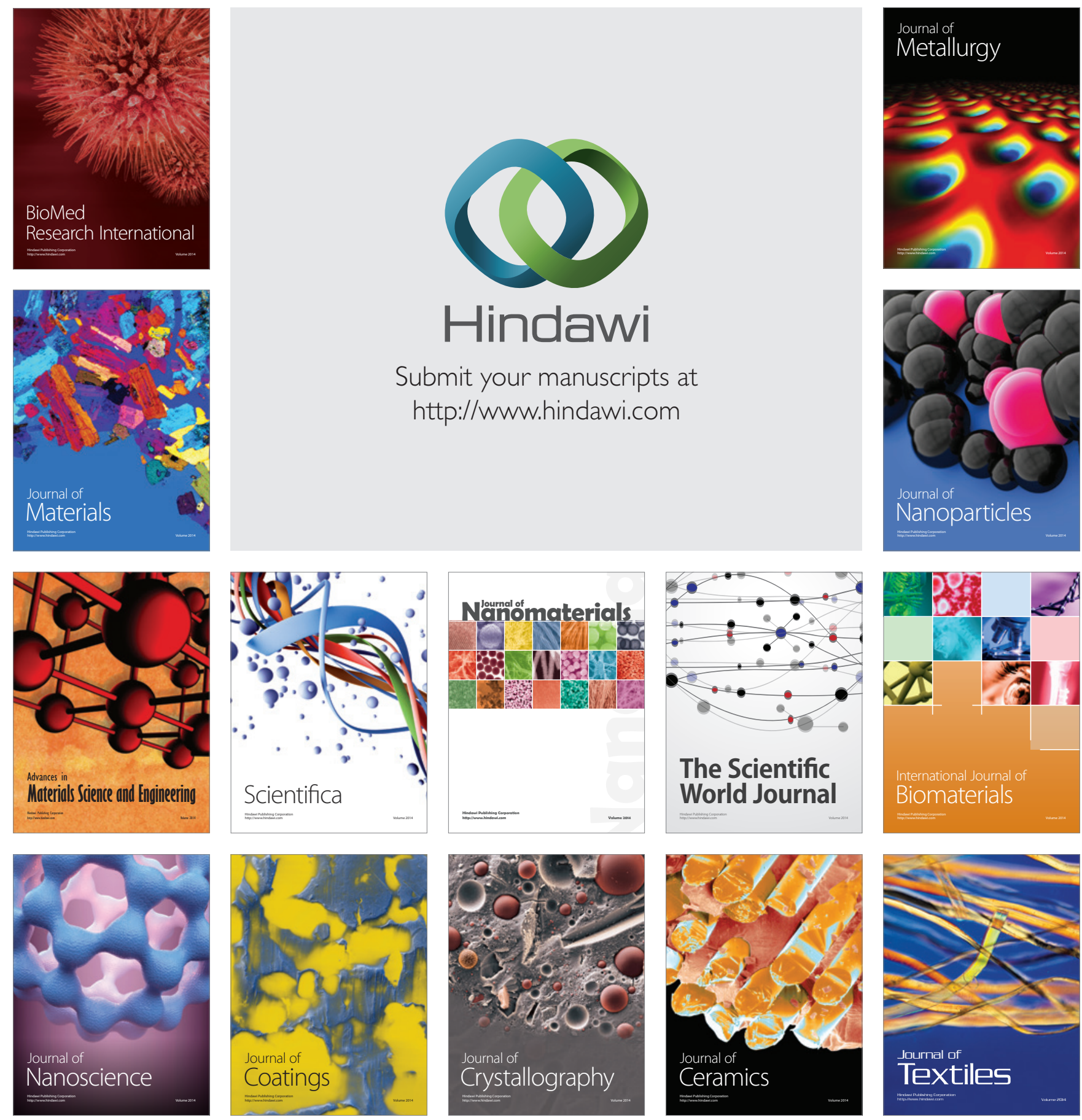